\title{
Engineering Features of Ancient Stupa Structure: A Review Based on Jethavana Vihara
}

\author{
K. Peiris, C. Jayawardana and S. Wijesinghe
}

\begin{abstract}
The ancient stupas, one of the largest brick structures even on a global scale, occupy a highly venerated position in Buddhist minds. Their structures have been technically analyzed to some extent, especially as a means of base knowledge for conservation purposes. In such technical studies, either stupa is considered as a single monolithic structure or a combination of monolithic structures. However archaeological excavations prove that the interior of a stupa consists of different zones with different materials in different layouts. The objective of this paper is to explore the possible functionality and structural interface between such zones and also to identify the philosophy and engineering traditions behind the design of these mega structures.
\end{abstract}

Key words; Stupa, Navanita clay, Ancient engineering traditions

\section{Introduction}

Among the objects of worship of the Buddhists, Sarirka Chethiya represents an edifice enshrining bodily relics of the Buddha. Stupa is the monument erected to place such relics in the most venerated manner. Because of this high religious importance attributed to the stupa, the construction is also associated with many religious rituals. Therefore any analysis of stupa construction should transcend the physical structural analysis and should cover such religious beliefs, attitudes and rituals also. However analyzing these structures in accordance with the basic mechanical perspectives will not present any hindrance in understanding their structural behavior, but due care should be exercised regarding the limitations of such an approach.

From a structural engineering point of view, there would be various stresses and strains developed within the stupa structure, due to natural changes such as internal expansion of the super structure, water absorption, deformations due to roots, weakened bricks, foundation settlement, etc., over a time span. On the other hand, archeological excavations of Jethavanarama stupa identified several internal structural zones.

The objective of this paper is to explore the functionality of those structural zones, in retaining the basic geometrical form of the stupa, under the internal stresses and strains due to the causes mentioned above. The contribution of navaneetha clay bond in such an exercise would also be addressed.

\section{Limitations of Modern Engineering}

In this expedition, limitations of modern engineering analysis should also be duly recognized. As an instance, if a structural failure of a stupa is considered, merely the structural engineering perspectives may not fully explain the reasons attributing to such failure. The immediate reason for failure would be the stresses developed in the structure. But why were such stresses developed? One reason would be the discrepancies in settlement. But why did such discrepancies occur? This may lead to an endless series of questions, for which the ultimate reasoning may not be within the scope of structural engineering, as such scope is limited to predict the behavioral patterns of structures under a given set of natural or man made circumstances.

Eng. K Peiris [B.Sc (Eng), MPlil, MA, MIE (Sri Lanka), C.Engl, presently Research Engincer, National Engineering Research and Development Centre [NERD], Ekaln.

Eng. C Jayawardana [B.Sc (Eng)Hons, MTech, MA, MIET, MIE (Sri Lanka), C.Engl, presently Projcct Manager, Cruickshanks Ceylon Pot. Ltd. Katunayaka.

Eng. S Wijesingha [B.Sc (Eng), MIE (Sri Lanka), C.Eng], presently Project Manager, Central Engineering Consultancy Burean [CECB], Colombo. 
Highlighting the similar phenomenon in theoratical physics, Richard Feyman [1] states,

"..What of the future of this adventure? What will happen ultimately? We are going along guessing the laws; how many laws are we going to have to guess? I do not know. Some of my colleagues say this fundamental aspect of science will go on; but I think there will certainly not be perpetual novelty, say for thousand years. This thing cannot keep on going so that we are always going to discover more and more laws."

This implies that the interpretation of natural or man made circumstances will vary from time to time and footing of engineering designs on such base has its own limitation.

\section{Rigidity vs. Flexibility of Structures}

In to present day engineering design, the interaction between nature and structure is forecast, then the boundary limits of natural phenomena determined and then the structure is designed to withstand such predetermined limits with a safety factor. Structures so designed are considerably solid but when the natural effects exceed boundary limits and safety factor, they will be subjected to sudden or gradual failure. Until then, minimum geometrical changes occur due to natural effects.

The ancient engineering design criteria adopted by our forefathers notes a clear deviation from the above methodology. Rather than constructing rigid structures, attempts were made to develop structures adapting to natural changes. Under such criteria, the study and understanding of the behavior of the natural environment may have not occupied the same importance it bears today. This may be a direct consequence of the effect of Buddhism by which these early engineers were nurtured, as a dhamma with anicia (impermanence), dukkha (unsatisfaction) and anatta (impersonality) as its basics.

Difference between rigid and flexible modes of construction could be demonstrated by an example. Figures 1 and 2 show a brick wall segment with thick layer and thin layer (like a layer of butter) of plaster respectively. An evenly distributed load is applied on both wall segments. If the retaining ground is distorted, then the wall segment in Fig. 1 tries to continue its geometry under the new situation. This is because of its rigid bond. As a result heavy bending moments will develop inside. If this is not to fail, the dislocation of ground should be predetermined and the wall should be specially designed and reinforced to withstand the new bending moments. Predetermination of actual ground dislocation may not be an easy task, prompting to making of a reasonable assumption for boundary values. If the actual dislocation exceeds such boundary value, the wall segment will fail. However the wall segment in Fig. 2 gets distorted along with the ground surface and the load is continued to be transferred to ground without failure of wall. This is even easier if brick length is shorter, and bending moment would be minimal. This phenomenon could also be further explained using the concept of statically indeterminate structures.
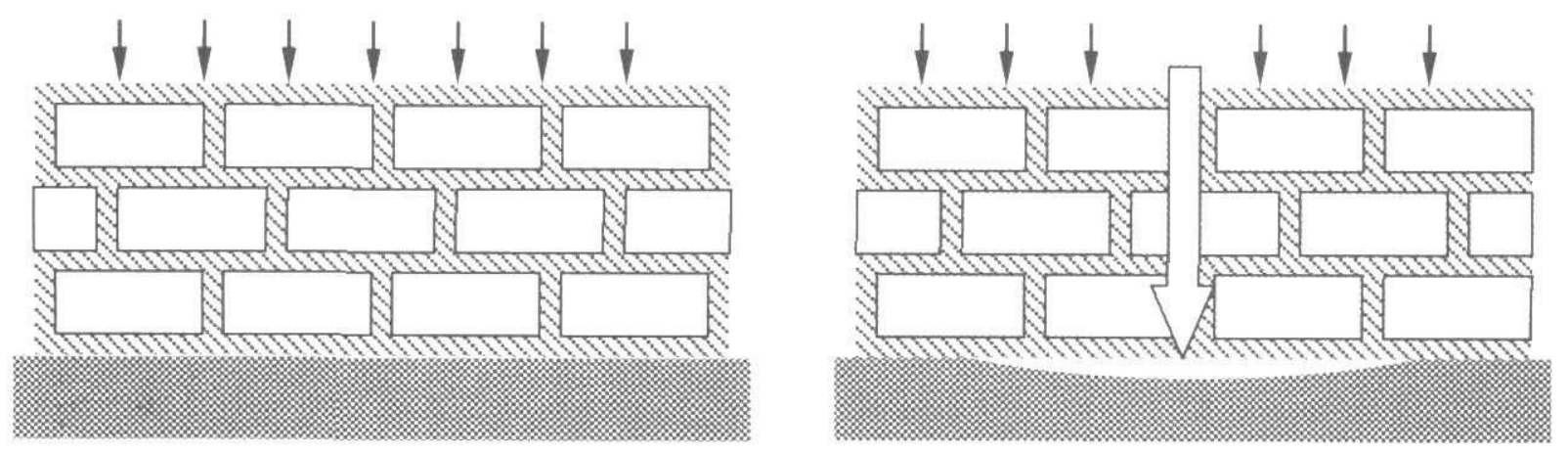

Fig. 1: Failure of rigidly bonded wall during ground distortion 

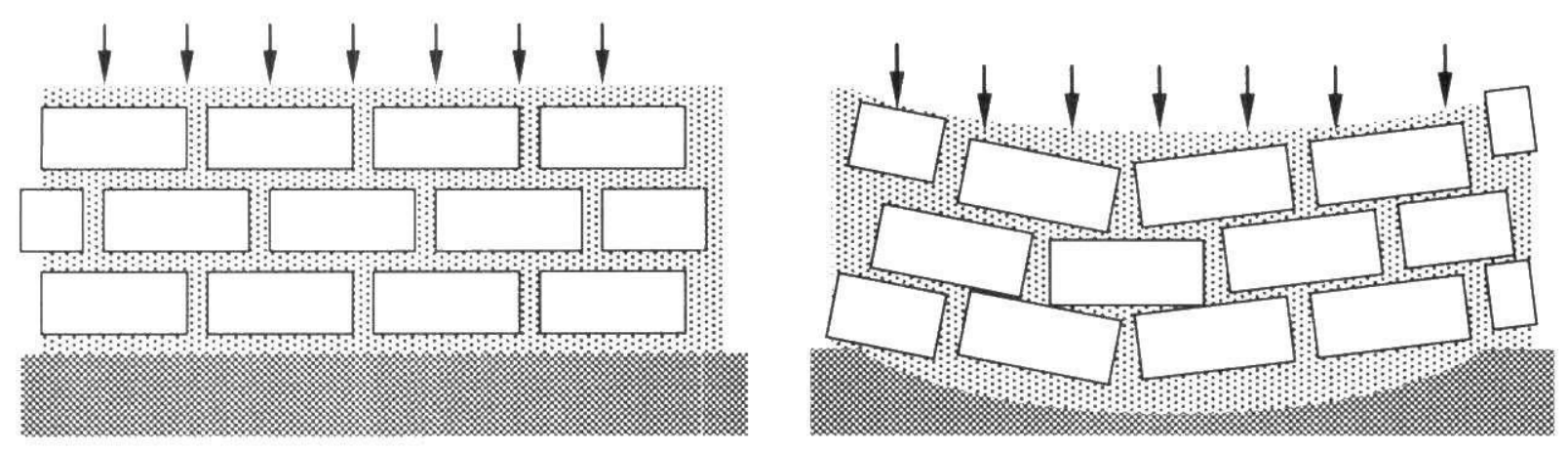

Fig. 2: Sustainability of slightly bonded wall during ground distortion

It should be noted that the wall segment in Fig 2 could be considered in dynamic terms but the same in Fig. 1 could be considered statically only. The only dynamic application to the latter is the time during the failure and until then the stresses, strains and other forces would be determined by a unique formula. But in the case of former, depending on the geometry of the structure, a range of formulae would explain the behavior of the structure.

\section{Analysis of Stupa Structure.}

In the light of the above background, the key theme of this paper could be considered, as special attention on the engineering technology and traditions adopted in the Jethavana stupa. This colossal stupa is attributed to the reign of King Mahasena (275-301AD), and is said to be the biggest stupa ever built, perhaps anywhere in the Buddhist world. As a brick monument still in existence, Jetavana stupa is the tallest of its kind in the world. Its height is given in the Mahavamsa [2] as 400 feet to the tip of its spire and 370 feet across its base. Its present height is estimated to be 232 feet.

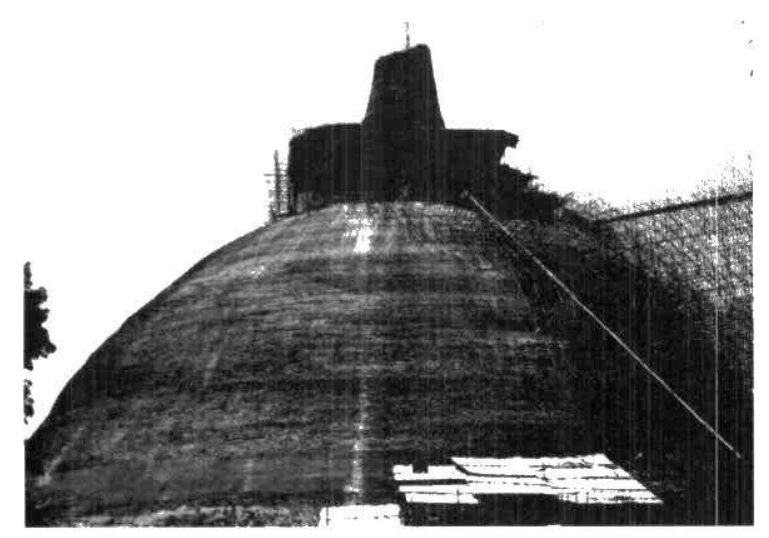

Fig 3: Jethavana Stupa during conservation

\section{Zonal Discrimination of Stupa Structure}

Fig. 5 shows a cross sectional view of Jetnavana stupa. According to the findings of archeological excavations, Gamlath [3] has developed zonal segregation of the stupa interior based on the constituents of such zones, which could be summarized as highlighted in Fig. 4. Composition of each zone as recorded in archeological excavation records, is further elaborated in Fig. 5

Zone 1: This forms the foundation of the stupa and is made of full size burnt bricks, neatly laid in stretcher courses. In some places, a single brick layer of $T$ shape has been laid and the surrounding space is filled with brickbats, clay and soil mix. Adjacent layers of such deviations are again of normal stretcher courses. Silva [4] notes the foundation starts from the bedrock lying approximately $28 \mathrm{ft}$. $(8.5 \mathrm{~m})$ below the stone paved terrace. Bricks are bonded together using navaneetha clay, a soft butter like substance, which is applied only in horizontal plane.

Zone 2: Cover of the stupa and composition of bricks and mortar is as same as zone 1, but in header courses. Silva [4] notes the average size of the bricks in this zone is larger $\left(18^{\prime \prime} \times 7{ }^{\prime \prime} \times 2-1 / 4^{\prime \prime}\right)$ compared to modern clay bricks and made of a finely graded aggregate of 70:30 sand clay mix. Compression tests revealed an average strength of $650 \mathrm{psi}(4.48 \mathrm{~N} / \mathrm{mm} 2)$. The bricks were bonded with a fine layer of navanita clay.

Zone 3: Bricks are smaller than the above two zones and not of even size. Still the bricks are bonded together using navanita clay, applied only in horizontal plane. 


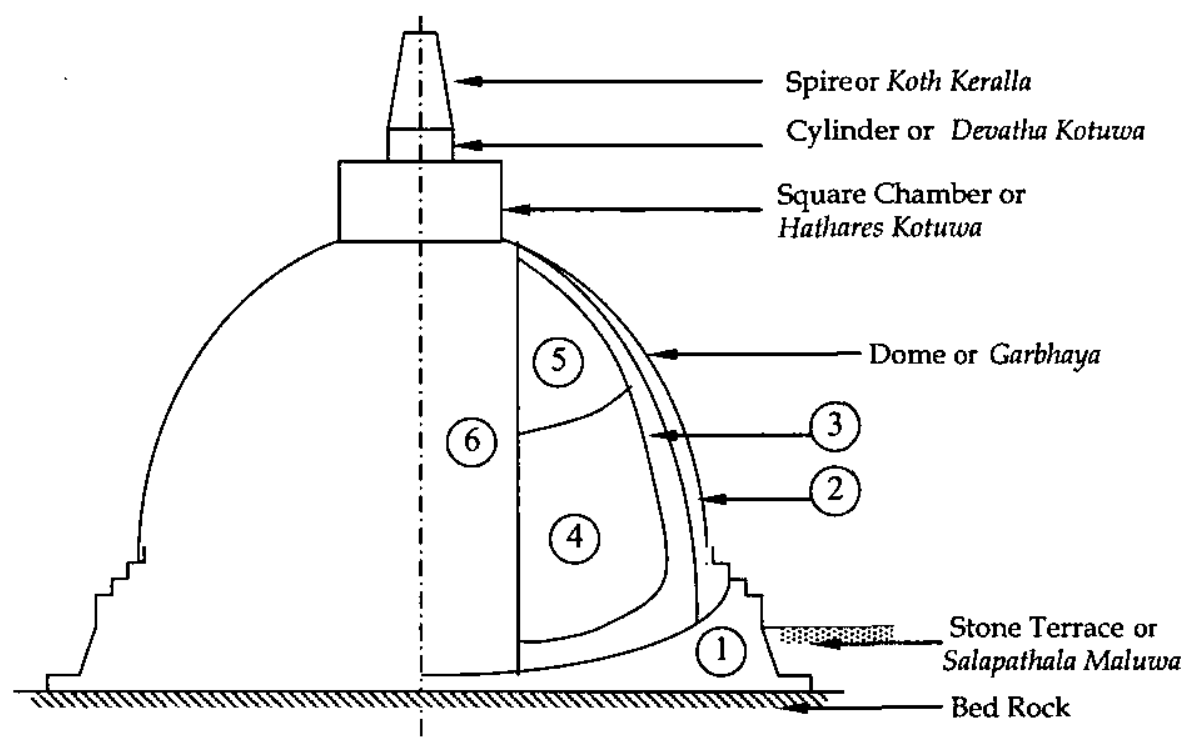

Fig. 4: Zonal discrimination of stupa dome, Jethavana stupa

Zone 4: Alternate layers of bricks and soil/clay mixture forms this zone. The brick size is smaller than that of zone 2 and zone 3 and thickness of soil/clay mixture is approximately $1 \mathrm{~cm}$. During the excavations, it was reveled that the brick layers have been horizontally displaced in some places.

Zone 5: This zone consists of two basic construction features. (1) Wall segments made out of burnt, neatly laid bricks and (2) mixture of brickbats, un-burnt bricks, clay and soil filling the spaces between those wall segments. These wall segments are positioned in several vertical planes and orientation is not specific. According to Paranavithana [5], availability of wall segments in this zone is a general observation in other large scale stupas also.
Zone 6: This is the zone directly under the square chamber and hence mainly responsible for the weight of upper parts of the stupa. Brick bats have been laid in a clay and soil mixture. In outer appearance, this seems as an adhoc earth fill but closure inspection reveals that the brick particles are embedded in clay/soil mix in an orderly manner.

The outer surface of the stupa was protected with a lime/sand plaster executed in three operations. The first leveling layer of coarse sand and lime $\left(3^{\prime \prime}-5^{\prime \prime}\right)$, a second layer of finer sand and lime $\left(1.5^{\prime \prime}-4^{\prime \prime}\right)$, finished off with lime putty.

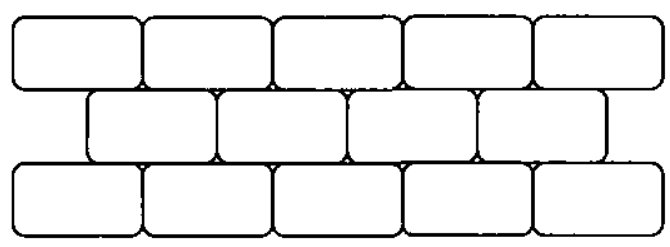

Plan view of general brickworks.

Elevation view of general brickwork. Layers are laid in stretcher courses.
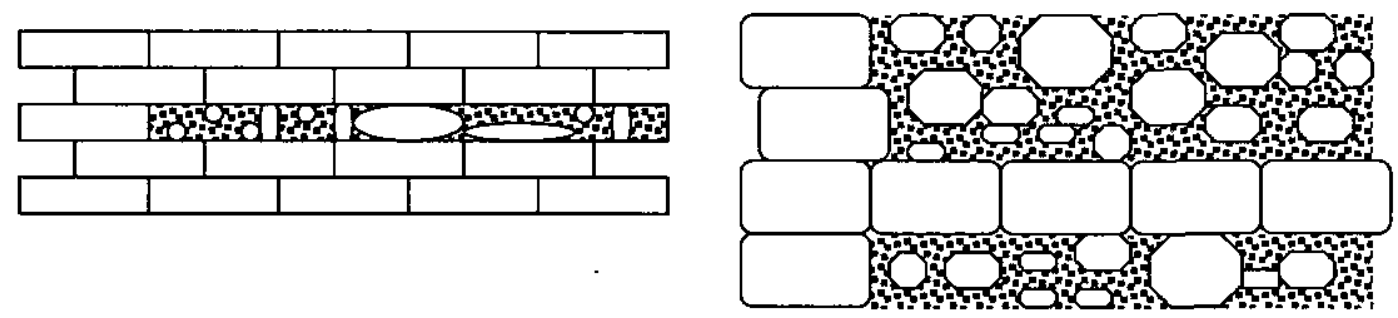

Plan view of $T$ shape brickworks.

Elevation view of $\mathrm{T}$ shape brickworks. This is restricted only to some places of this zone. 
Zone 2

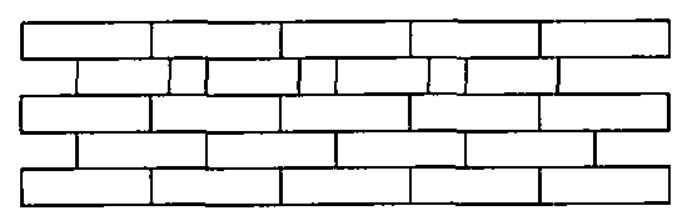

Elevation view of general brickworks. All layers are laid in stretcher courses.

Zone 3

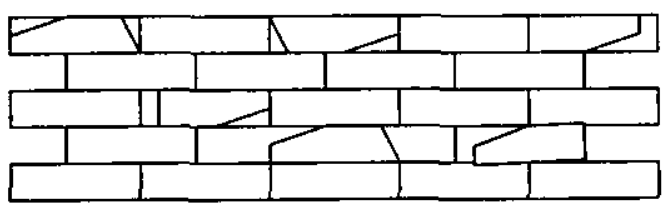

Elevation view of general brickworks.

Zone 4

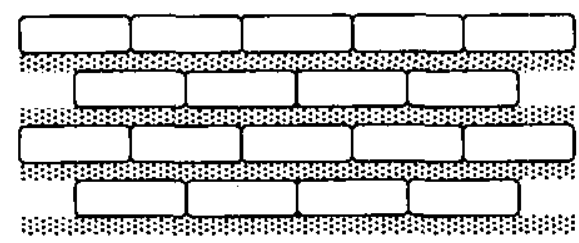

Elevation view of general brickworks.

Zone 5

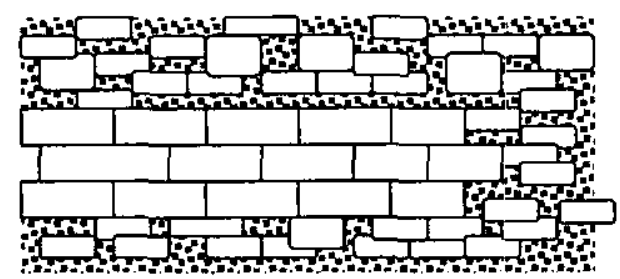

Elevation view of general brickworks.

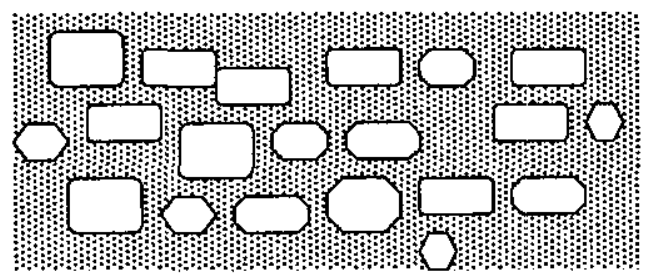

Elevation view of general brickworks.

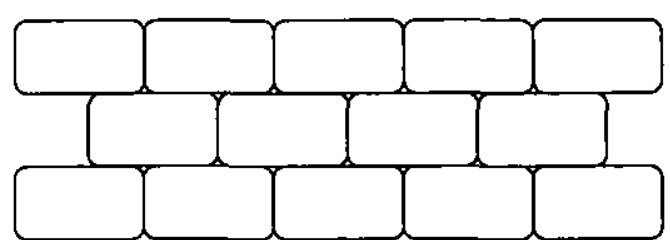

Plan view of general brickworks.

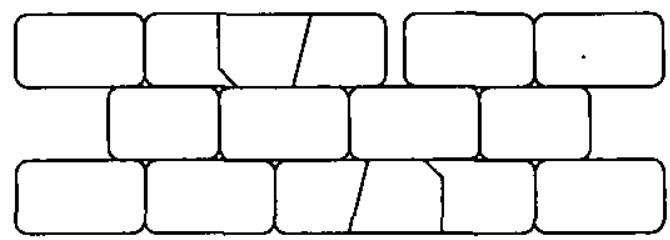

Plan view of general brickworks.

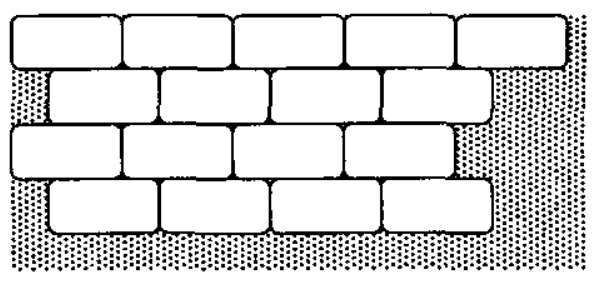

Plan view of general brickworks.

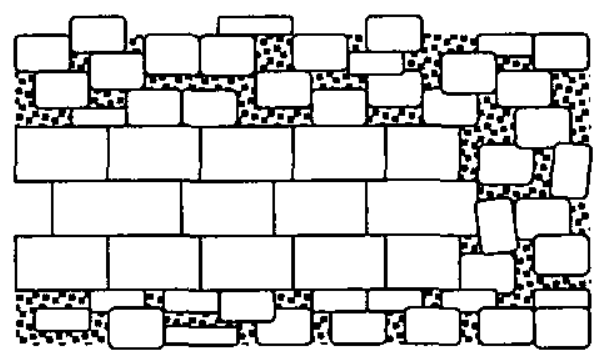

Plan view of general brickworks.

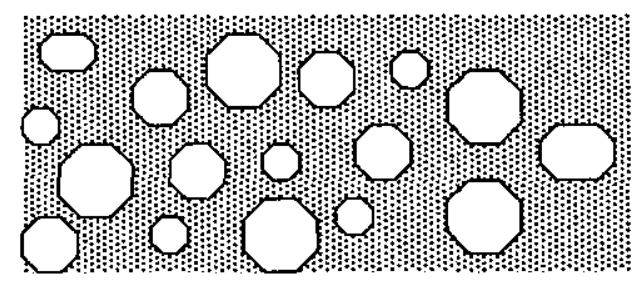

Plan view of general brickworks.

Fig. 5: Composition of different zones 


\section{Properties of Navanita clay bond}

Apart from the zonal discrimination, the type of bonding used in brickwork is also important in studying structural stability of a stupa. In Mahavamsa [2], elaborating the construction procedure of Ruwaweliseya, the extensive usage of navanita mattika as bonding material has been mentioned. Silva [6] exploring the features of navanita clay notes that this was used in many ancient stupa constructions including the mega scale Ruwanweliseya, Abayagiriya and Jethavana Vihara. As this substance is very soft, it fills the air gaps between the two bricks. Such arrangement bonds the units together more in the form of a pliable paste having the properties of surface tension than by a hardening substance with an added thickness between the bricks. This process produces the perfect homogeneity of the brick-upon-a-brick bond. It also discourages any horizontal movement fixed by surface tension. The fluidity of the mortar was ensured as it was clay which had minimal hardening properties unlike lime or cement. Abeyrathna [7] notes the constituents of navanita clay as $\mathrm{SiO}(68.21 \%)$, $\mathrm{CaO}(12.05 \%)$ and others $(19.74 \%)$.

Further, due to the fact that clay was perfectly pliable, there was no possibility of any of the brick masonry hardening to a monolithic mass. The plasticity of the clay is such that any major movement within the mass of brickwork could take place without fracturing the individual bricks and the pliable clay filling the voids as originally as is possible. During the excavations, it has been noted that the application of navanita mortar was limited only to the horizontal plane between brick layers avoiding vertical bonds. Under this arrangement, bricks are mainly subjected to compressive stresses and less prone to tensile stresses derived by bonding.

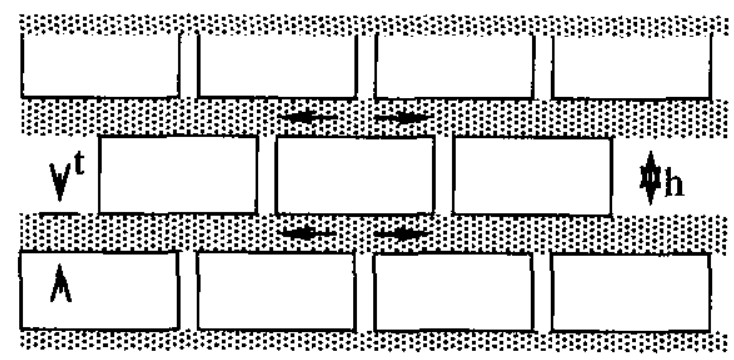

Fig. 6: Application of navanita in ancient brickwork
Formulating the brickwork strength based on elastic analysis, Hendry et al [8] notes that $\sigma_{c}$, the limiting compressive strength of a brickwork is given by,

$$
\sigma_{c}=\frac{\sigma_{c}{ }^{\prime}}{v_{b}+\frac{v_{m} \cdot m-v_{b}}{1+r \cdot m}}
$$

Where,

$\mathrm{Vb}, \mathrm{Vm}=$ Poisson ratio of bricks and mortar $\sigma_{c}=$ Maximum tensile in bricks

$\sigma_{c}{ }^{\prime}=$ Compressive capacity of bricks

$r=$ the ratio of mortar/brick thickness

by minimizing the thickness of mortar, $r$ could be maximized and hence the limiting compressive strength oc could be maximized. Application of navanita clay ensures this implication.

\section{Evaluating the structure of stupa in dynamic terms}

Understanding the internal structure of a stupa and the action of navanita clay bond forms the basis to evaluate the behavior of a stupa structure in dynamic terms. Under such evaluation, the behavior of stupa structure under the changing conditions of external environment such as expansion due to water and heat, decay of bricks in between, settlement, etc., has to be considered.

As evident from Fig. 7, loads of the spire, cylinder and square chamber are transferred to the foundation through zones 4,5 and 6. Due to this load, zone 6 may expand radially. Radial forces due to such expansion are absorbed by zone 5 in the upper portion. The wall segments in this zone will prevent internal lateral movements due to radial forces. In the lower portion, radial forces are absorbed by zone 4, consisting of alternating layers of bricks and clay/soil mix, again preventing any lateral forces towards the cover. Therefore, there will be minimum lateral forces on the zones 2 and 3 . These zones are actually the sheath of the stupa, protecting the internal structure from water seepage, etc., and maintaining the shape of the stupa. As such, damages to these zones, as evident before the recent conservations, had not caused a structural failure of the stupa as a whole. 


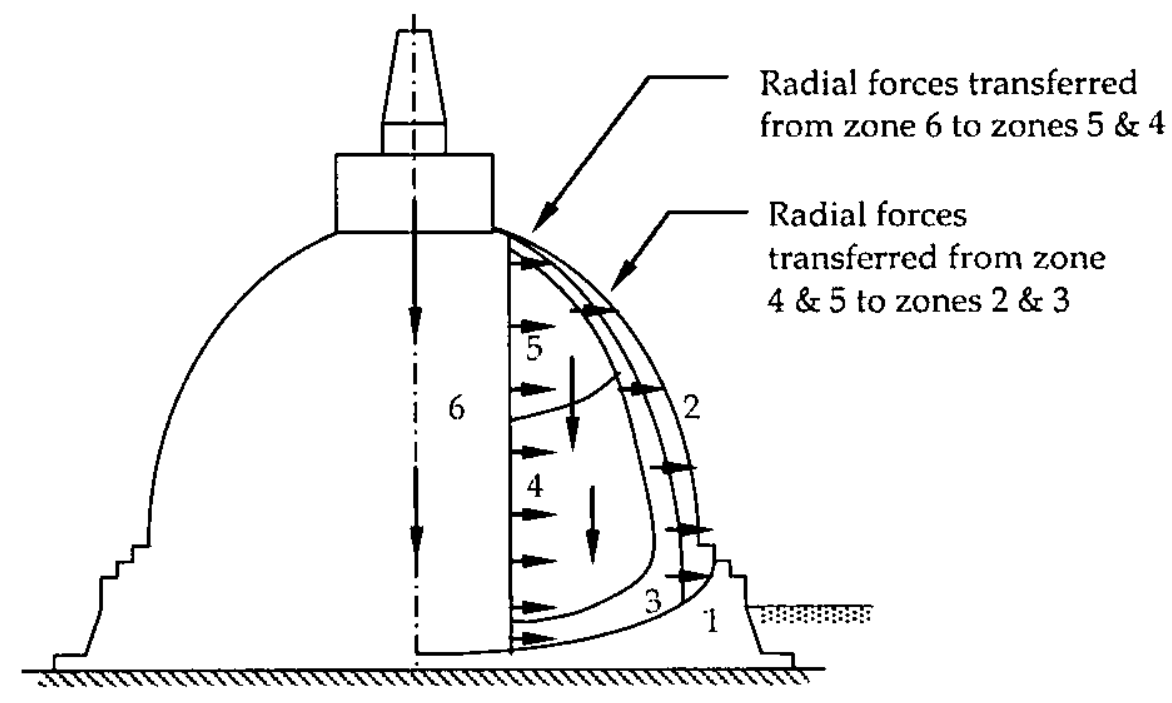

Fig. 7: Force distribution inside the stupa dome

Apart from the compressive forces due to load of upper parts, there are internal stresses and differential movements developed due to expansion and thermal action. Also if water leaks into the middle part, frictional and cohesive components related to Morh Coloumb analysis of soil will become weak and the unit weight will increase.

All these factors contribute to the increase in the radial forces on zone 3 and thereby zone 2 . If these zones are not flexible enough to change their shape according to those forces, there will be severe bending stresses developing ultimately leading to structural failure. The behavior of navanita bond is of vital importance in this respect. Stresses developed due to expansion of clay will be almost released if the zones 2 and 3 are expandable. If zones 2 and 3 are not flexible, internal soil may pass to the passive stage from active, increasing the radial loads on zones 2 and 3 greatly.

Zones 2 and 3 consist of bricks bonded by navanita only in the horizontal plane. This bonding method and the flexibility of navanita enable these zones to act in the similar manner of a rubber strip in the horizontal plane, enabling the outer brick layers to distort in response to the internal forces, avoiding formation of high bending moments. As Fig. 8 indicates, forces coming from expansions of zone 4,5 and $6\left(\mathrm{~F}_{\mathrm{R}}\right)$ will be compensated by development of hoop tensile forces (FH) and by shear forces developed from the adjacent top and bottom brick layers (FS). This is further elaborated in Fig. 9. If these outer brick layers are not able to change their geometry, bending moments will develop creating high bending stresses, which may crack the outer brick layers vertically. Deflection of brick layers will reduce bending resistance, thus reducing bending stresses. Radial forces are compensated by frictional forces and induced hoop tensile stresses.

Godakumbura [9] notes another feature of the outer brick layers, during the conservation process of the Abayagiri stupa. Accordingly unburned bricks were included with an intensity of 6-8 per $\mathrm{m}^{2}$ and $1-2$ per $\mathrm{m}^{2}$ around $30 \mathrm{~m}$ and $10 \mathrm{~m}$ above from the ground respectively. The given interpretation for this presence is to absorb the water during the rainy season avoiding the seepage into inner parts. This water will be released to the atmosphere during drying, hence proving that the structural constituents were allocated in line with maintaining harmonious interaction with natural changes.

With the view of understanding the behavior of brickwork of outer layer of stupa, a simple experiment was performed at NERDC, Ekala. Two wall segments were prepared using conventional cement mortar (cement:sand 1:5) and in traditional clay mortar (antclay:lime 6:4, without vertical bonding). Radial force on both walls was applied and mid span deflection was measured for a range of radial forces. Results thus obtained were plotted as Fig. 10.

Although the maximum withstanding force is higher in cement bonded wall, the flexibility is low. In cement bonded wall, failure occurred 


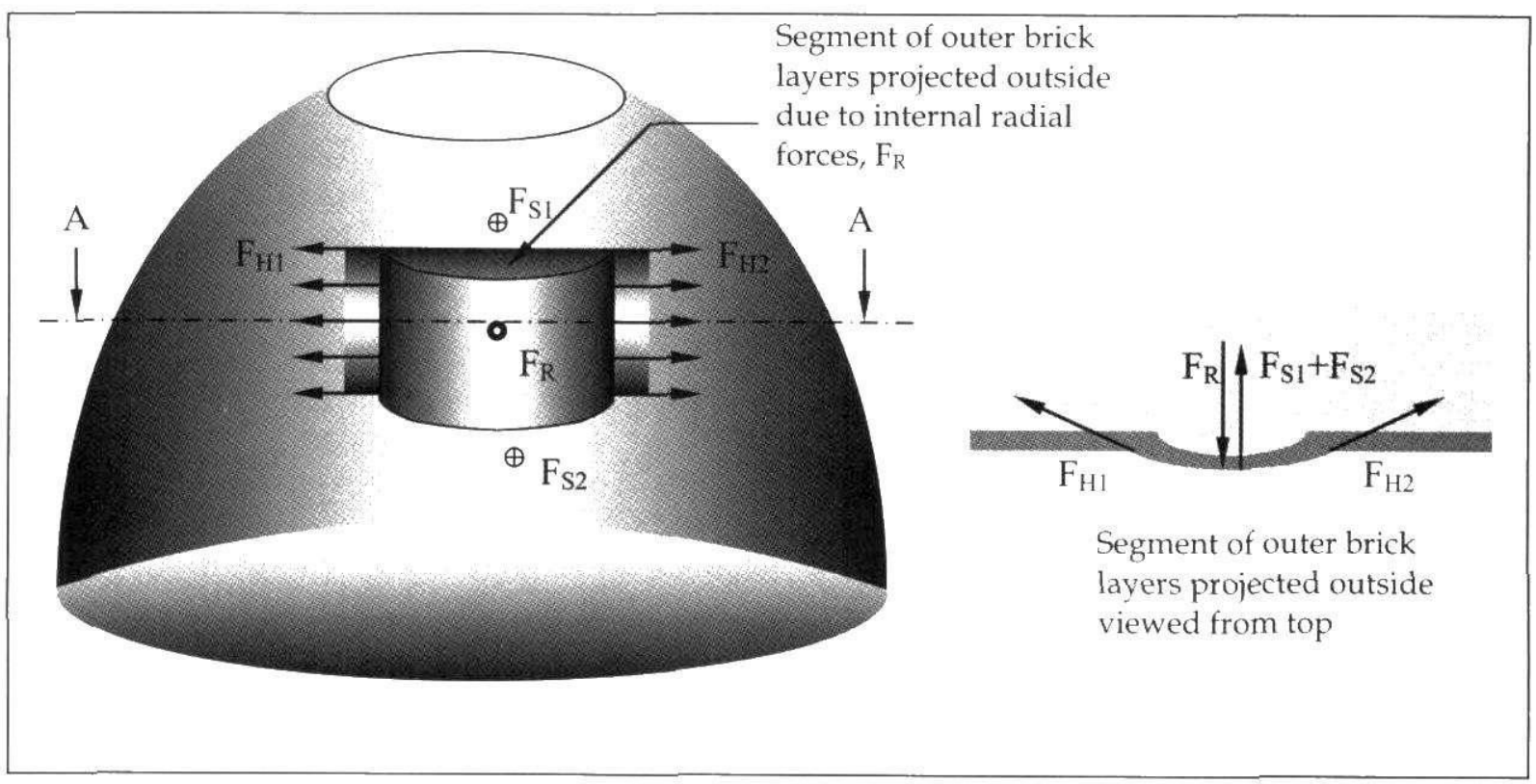

Fig. 8 Expansion of a segment of outer brick layers due to radial shear forces

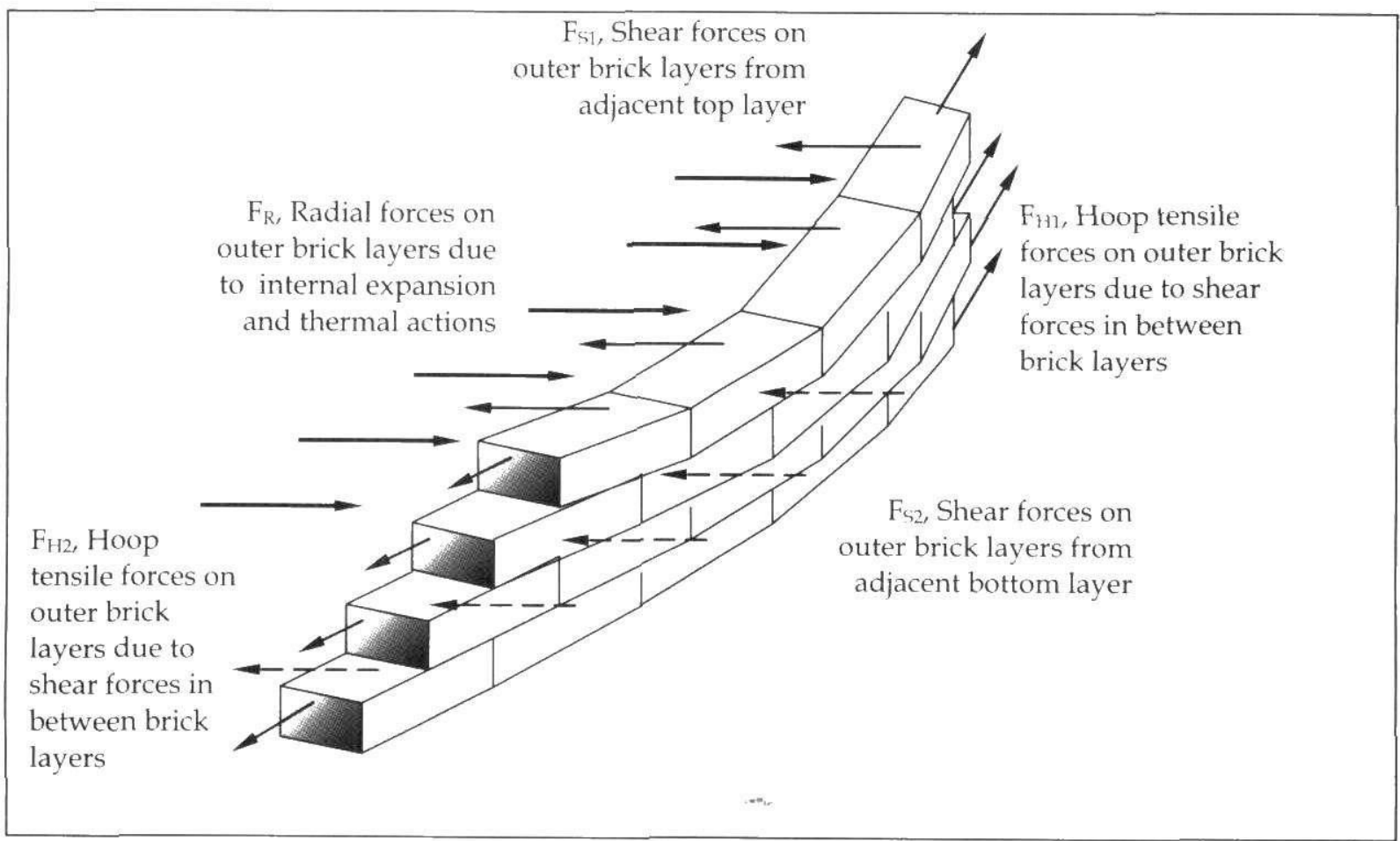

Fig. 9: Details of brick layer geometry change due to internal forces

due to bending moments in the brick-mortar unit, while in the clay bonded wall, the failure was due to yielding of bricks in thin mortar matrix. This flexibility is also important in the analysis of stupa structure as flexibility reduces the forces acting by releasing the stresses. For flexible structures, when stresses are imposed, dimensional changes may be minimal and structural stability will be maintained. However, when such stresses are imposed on a rigid structure, it will attempt to maintain the dimensional accuracy as much as possible, and when the dimensional accuracy cannot be maintained, the structure would fail. 


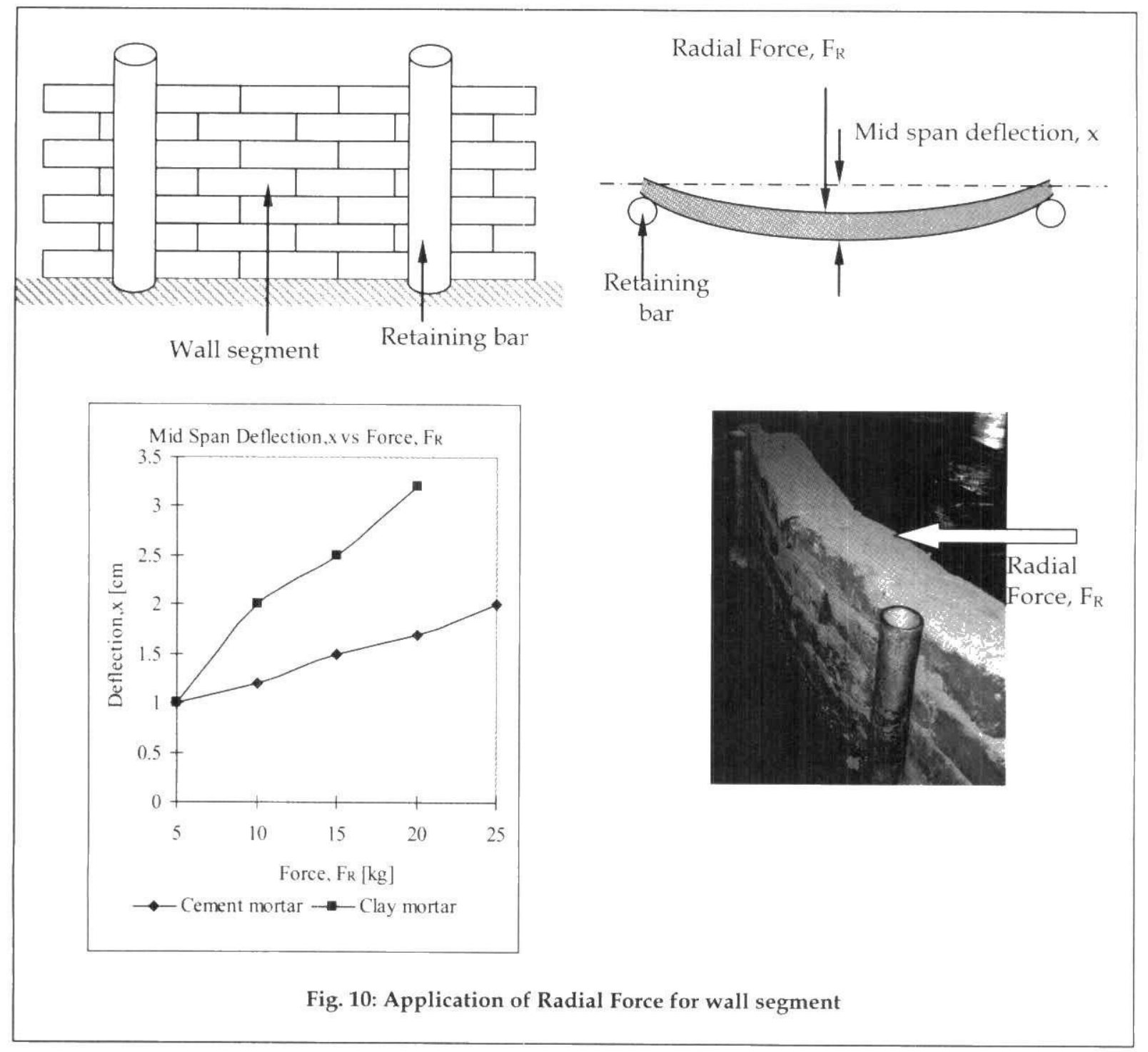

\section{Comparison with current construction methods}

Severe failures in modern day brick work as shown in Fig. 11 occur due to the failure of brick mortar. This is due to tension caused by restricted movement of mortar between brick layers and/or differential internal horizontal movement due to Poisson effect (as differential lateral movement will create horizontal tensile stresses). However, if vertical bonding (mortar) is not provided, second type of tensile stresses will not develop.

In ancient stupa, even though tensile (horizontal) stresses may appear due to restricted mortar movements imposed by the top and bottorn brick layers, no similar failures will occur as no

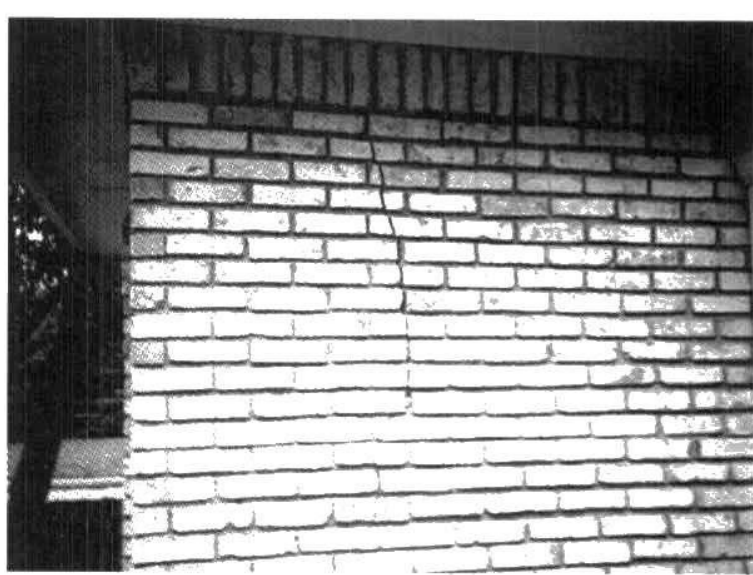

Fig 11: Failure of modern brickwork vertical bonding were provided in brickwork. 


\section{Action of "soft pockets"}

As detailed above, the stupa could not be considered as a monolithic structure but a structure with zonal discrimination. The constituents and their respective arrangement in some zones, could be treated as "soft pockets". These soft pockets serve to eliminate the formation of internal stress intensity of significantly high values, as well as to avoid propagation of internal differential movements. The action of "soft pockets" could be further elaborated using the concept of virtual work. In Fig. 12, a soft pocket is shown inside a rigid body, and Pi's $(i=1,2,3, \ldots, i, . ., n)$ are the external forces acting on the soft pocket. Now if some expansion or settlement (or any other effect) inside the soft pocket or in the rigid part near the soft pocket occurs, some of these Pi's will try to displace slightly and LHS terms of the equation (2), Pi.dri, will start to appear. Due to this slight displacement of some Pi's, strains will develop, of which the quantification will be as per the RHS of the equation. Therefore, the other Pi's may not get effected, i.e., the stresses will not propagate throughout the region.

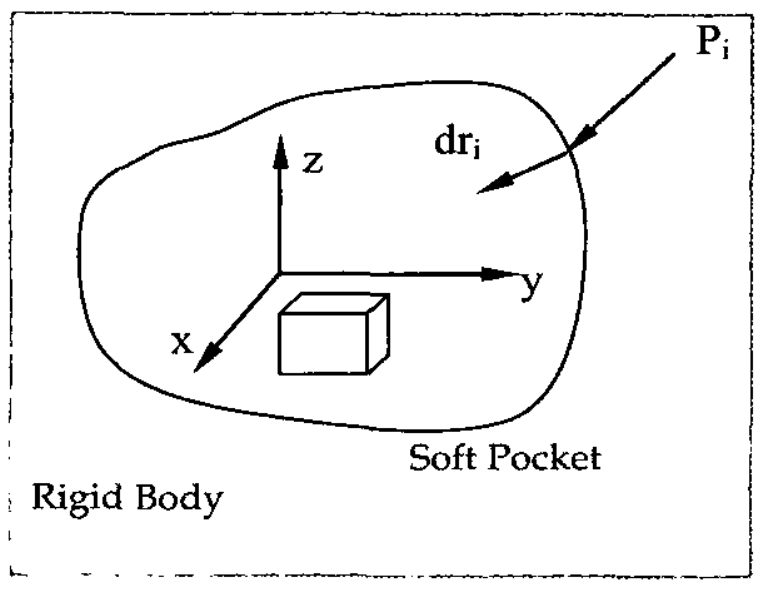

Fig 12: Application of Pi on a soft pocket inside a rigid body

$$
\begin{aligned}
& \sum_{\mathrm{j}} \cdot \mathrm{dr}_{\mathrm{i}}=\int_{\mathrm{v}}\left(\sigma_{\mathrm{x}} \delta \varepsilon_{\mathrm{x}}+\sigma_{\mathrm{y}} \delta \varepsilon_{\mathrm{y}}+\sigma_{\mathrm{z}} \delta \varepsilon_{\mathrm{z}}+\zeta_{\mathrm{xy}} \delta \gamma_{\mathrm{xy}}+\right. \\
& \left.\zeta_{\mathrm{xz}} \delta \gamma_{\mathrm{xz}}+\zeta_{\mathrm{yz}} \delta \gamma_{\mathrm{yz}}+\rho g \delta W\right) \mathrm{dv} \\
& \varepsilon_{\mathrm{x}}=\mathrm{du} / \mathrm{dx}, \varepsilon_{\mathrm{y}}=\mathrm{dv} / \mathrm{dy}, \varepsilon_{\mathrm{z}}=\mathrm{dw} / \mathrm{dz} \\
& \gamma_{\mathrm{xy}}=\mathrm{du} / \mathrm{dy}+\mathrm{dv} / \mathrm{dx}, \gamma_{\mathrm{xz}}=\mathrm{du} / \mathrm{dz}+\mathrm{dw} / \mathrm{dx}, \gamma_{\mathrm{yz}} \\
& =\mathrm{dv} / \mathrm{dz}+\mathrm{dw} / \mathrm{dy} \quad \ldots \ldots \ldots(2) \\
& \text { Where, } \\
& \mathrm{P}_{\mathrm{i}}=\text { External forces } \\
& \mathrm{dr}_{i}=\text { Slight displacements (excluding slipping } \\
& \text { components) }
\end{aligned}
$$

$\sigma_{x}, \sigma_{y}, \sigma_{z}=$ Normal stresses in $x, y, z$ directions

$\mathrm{u}, \mathrm{v}, \mathrm{w}=$ Displacement in $\mathrm{x}, \mathrm{y}, \mathrm{z}$ directions respectively

$\zeta_{x y}, \zeta_{x z}, \zeta_{y z}=$ Shear stresses in planes parallel to $x y, x z$ and $y z$ respectively

$\rho=$ Density of material

$\mathrm{g}=$ Acceleration due to gravitation

If the part represented as soft pocket was a rigid body, terms related to the strains would have been zero, making the slight displacements of Pi's impossible. Consequently factors now trying to displace $\mathrm{Pi}^{\prime}$ 's will result in the change of $\mathrm{Pi}^{\prime}$ 's significantly. According to the equilibrium equation, other Pi's will also be changed and the final result would be stresses propagating all over the structure. This arrangement is valid even if the "soft pocket" is made out of loosely bonded rigid parts, such as bricks bonded in navaneetha.

\section{Conclusion}

Now, it is evident that the following applications would become important only when the stupa structure is dynamically considered, (1) functionality of navaneetha clay bond, (2) its application only in horizontal plane and (3) application of unburnt bricks in between, creating soft pockets. In an overall view, in ancient stupa structure, stress releasing mechanisms are in built and hence less stress concentration occurs. This has been achieved through zonal construction and the application of navaneetha bond. The rigid burnt bricks bonded by thin navaneetha mortar with other elements such as un-burnt bricks, brick bats, clay (soft pockets) have provided the dynamic character for the structure while maintaining its geometrical stability. This entire phenomenon leads us to believe the design philosophy adopted by our forefathers in constructing mega structures had a different approach, compared with today. Rather than designing the structures to tolerate predetermined environmental parameters with adequate safety factors, flexibility was maintained so that the structure itself could change in line with the environment. Exploring the nature with the view of understanding its behavior in fixed terms may not be required in such execution.

Findings of this paper could be further studied in two main areas. (1) The zonal discrimination as indicated in Fig. 5 is based on observations 
during excavations, limited to various localities. The generalization of such details to form six zones was done by authors and if these details could be further elaborated, the zone separation would be more accurate. (2) Usage of better analytical tools such as Finite Element Method will reveal the load distribution and inter zonal interfacing on a better footing. For this purpose, FEM should be developed considering the stupa as a varying composition rather than a single or as a combination of monolithic structures.

\section{References}

1. Feyman, R., The Character of Physical Laws, Cambridge, Massachusetts: The M.J.T Press, 1967.

2. Mahavamsa, The Great Chronicle of Ceylon, Wilhem Geiger, 1912, republished by Buddhist Cultural Centre, Dehiwala, Sri Lanka, 2003

3. Gamlath, D.P., Jethavana stupa garbaye idikirim thakshana karma, Sanskruthika Puranaya, Volume 2, Issue 8, Central Cultural Fund, 1997 OctberDecember
4. Silva, W.N.G., Conservations of Ancient Dagobas in Sri Lanka, Engineer - Vol. XXXX, No. 03, 2007, The Institute of Engineers, Sri Lanka

5. Paranavithana, S., The Stupa In Ceylon, Archeological Department of Ceylon, 1963.

6. Silva, R., Brick - A Unit of Construction in Ancient Sri Lanka, Men and Monuments, D.T Devendra, A Centennial Tribute, Central Cultural Fund, Sri Lanka, 2001

7. Abeyratne, M., Analysis of Lime Mortar in Ancient Stupas in Sri Lanka, Research Paper No. CH/2, UNSCO-Sri Lanka Project of the Cultural Triangle, Colombo, 1982 (Unpublished)

8. Hendry, A.W., Sinha, B.P., Davies, S.R., Load Bearing Brickwork Design, 2nd Edition, Ellis Horwood Linuited, England, 1987

9. Godakumbura, R., Abayagiri stupa garbha sanrakshanya, Sanskruthika Puranaya, Volume 2, Issue 5, Central Cultural Fund, 1997 January -March. 